Int J Infect Microbiol 2012;1(2):49-53

\section{Status of tuberculosis in bovine animals raised by tuberculosis infected patients in Western Chitwan, Nepal}

\author{
Pandey G, ${ }^{1}$ Dhakal S, ${ }^{1,3}$ Sadaula A, ${ }^{1}$ KC G, ${ }^{1}$ \\ Subedi S, ${ }^{1}$ Pandey KR, ${ }^{2}$ Dhakal IP1
}

\footnotetext{
${ }^{1}$ Institute of Agriculture and Animal Science (IAAS), Tribhuvan University, Rampur Campus, Chitwan, Nepal, ${ }^{2}$ Veterinary Officer, Central Veterinary Laboratory, Tripureshwor, Kathmadu, Nepal, ${ }^{3}$ Veterinary Officer, National Zoonoses and

Food Hygiene Research Center (NZFHRC), Kathmandu, Nepal
}

*Correspondence to: Dr. Ishwari Prasad Dhakal, Department of Veterinary Medicine and Public Health, Institute of Agriculture and Animal Science (IAAS), Tribhuvan University, Chitwan, Nepal. E-mail: ipdhakal5@gmail.com, Tel. No.: (+977)-9855056168

\begin{abstract}
INTRODUCTION: Bovine tuberculosis (bTB) is an important public health concern worldwide. This study was conducted to determine the status of bTB in animals raised by tuberculosis patients in Western Chitwan, Nepal.

MATERIALS AND METHODS: This cross-sectional study was conducted from August, 2011 to January, 2012. A total of 100 bovines (cattle and buffalo) raised in 60 farms of tuberculosis patients were tested with single intradermal tuberculin test considering various animal factors. Well designed questionnaire survey was taken with 70 tuberculosis patients of same 60 families focusing knowledge, awareness and various practices related to bovine tuberculosis.
\end{abstract}

RESULTS: Overall 15\% bovines were positive for tuberculosis (13.6\% cattle and $15.4 \%$ buffaloes). Age of animal was significantly associated with tuberculosis $(\mathrm{p}<0.05)$ while sex and species were not. $24 \%$ tuberculosis patients had raw milk consuming habit while very few of them (9\%) were aware of zoonotic aspect of bovine tuberculosis.

CONCLUSIONS: There is high chance of tuberculosis transmission form animals to humans or vice versa. Further detailed study is needed in large scale with stronger intersectoral collaboration of medical and veterinary health sector to determine the scale of problem and find out prevention and control strategies against zoonotic tuberculosis.

KEY WORDS: Tuberculosis, Mycobacterium bovis, Tuberculin test, Zoonosis

Article submitted 2 October. Reviewed 30 October. Author correction 1 November. Final version accepted 29 November 2012 


\section{INTRODUCTION}

Bovine tuberculosis (bTB) is a chronic disease of animals caused by infection with the slow growing obligate intracellular bacterium Mycobacterium bovis. M. bovis is highly adapted pathogen having world-wide distribution and is a major, costly infectious disease of cattle and other domestic animals causing devastating economic loss. ${ }^{1,2}$ bTB remains an important public health concern worldwide. ${ }^{3}$ Though, human tuberculosis is mainly caused by $M$. tuberculosis, in regions where bTB is prevalent in animals, human TB cases due to $M$. bovis may occur. ${ }^{4}$ The main risk factors for bTB transmission were found to be the consumption of unpasteurized/poorly heat treated milk, close contact with infected animals and lack of proper farm hygiene and management. 5,6

Human infection is primarily through ingestion and secondly by inhalation especially in children. ${ }^{7}$ The ease and frequency of the spread of bTB from animals to humans in an uncontrolled environment makes it one of the important zoonoses. Since long bTB is prevalent among cattle and buffaloes in Nepal. ${ }^{8}$ However, till date no studies have been done to the extent so as to support or rule out the zoonosis of bovine tuberculosis in Nepal. In these perspectives, this study was carried out to determine the status of bovine tuberculosis in animals raised by the tuberculosis infected patients.

\section{MATERIALS AND METHODS}

Study area: This is a cross sectional study carried out in a six month period from August, 2011 to January, 2012. The site selected for this study included six VDC's of Western Chitwan namely Sharadanagar, Mangalpur, Gunjanagar, Divyanagar, Phulbari, and Shivanagar. While selecting the study area following things were taken under consideration: number of bovine population to be large, major pocket area for milk and meat production and number of TB patients getting DOTs to be higher.

Sampling of animals: A total of 100 animals were selected for tuberculin test within six month period from 60 TB infected patients farms. The secondary data of tuberculosis infected persons and their contact details were obtained from major DOTs centre and District Public Health Office of Chitwan district. They were visited personally. For the study cattle and buffaloes of age more than six month and of both sex were selected randomly within the study area on proportional basis. Diseased, young calves below six month age, animals in advanced pregnancy and those within six weeks post partum were excluded so as to avoid false negative reaction. Possible sampling bias was introduced when the owner himself/herself decided which animals fulfilling the inclusion criteria to be tested. Single intradermal tuberculin test was carried out to determine the status of bovine TB.

Questionnaire survey: A well formulated and pretested questionnaire was surveyed among the $60 \mathrm{~TB}$ infected patients from where animals were sampled. The questions were focused on determining their knowledge, awareness and practices with respect to tuberculosis in general and bovine tuberculosis in particular.

Single intradermal tuberculin test (SITT): The procedure used was as described by Radostits et. al. About $12-15 \mathrm{~cm}$ apart, on the cervical area skin was clipped, washed with soap and disinfected with $70 \%$ ethanol. The initial skin thickness was measured by Vernier Callipers followed by an intradermal injection of $0.1 \mathrm{ml}$ bovine purified protein derivatives (PPD) with a tuberculin syringe and needle. The site of injection was marked with permanent marker to ease the location of injection in subsequent readings. Subsequent readings of the skin thickness were recorded in 72 hours post injection. The data was compiled and the visible, palpable or measurable change in skin thickness was noted. The animals reacting to the tuberculin with the visible edematous change as described by Radostits et al. or enlargement in skin thickness by $4 \mathrm{~mm}$ or more in 72 hours as described by Chakrabarti were declared positive reactors. Mild reactors were indicated by skin thickness increment of between 2 and $4 \mathrm{~mm}$ were also taken positive while increases in skin thickness less than $2 \mathrm{~mm}$ were declared as negative reactors. ${ }^{7,9}$

Ethical approval: This study was carried out as part of partial fulfillment of degree of Bachelor of Veterinary Science and Animal Husbandry (B.V.Sc. \& A.H.) and approved by the Institute of Agriculture and Animal Science (IAAS) internship committee. Consents of the tuberculosis affected persons were taken before moving ahead to questionnaire survey and/or tuberculin test in animals.

Statistical analysis: Statistical analyses were carried out using the Microsoft Excel-2007 and SPSS-19 version. Descriptive statistics was used and data were considered significant at $5 \%$ level of 
Table 1. Tuberculin reactions among cattle and buffaloes

\begin{tabular}{|c|c|c|c|c|c|c|}
\hline \multirow{2}{*}{ Species } & \multirow{2}{*}{ Sex } & \multicolumn{4}{|c|}{ Reaction } & \multirow{2}{*}{$\begin{array}{c}\% \\
\text { Positive }\end{array}$} \\
\hline & & Positive $(\geq 4 \mathrm{~mm})$ & Mild (2-3.9mm) & Negative $(\leq 2 \mathrm{~mm})$ & Total & \\
\hline \multirow[t]{3}{*}{ Buffaloes } & Male & - & - & 13 & 13 & 15.4 \\
\hline & Female & 7 & 5 & 53 & 65 & \\
\hline & Total & 7 & 5 & 66 & 78 & \\
\hline \multirow[t]{3}{*}{ Cattle } & Male & 2 & - & 4 & 6 & 13.6 \\
\hline & Female & - & 1 & 15 & 16 & \\
\hline & Total & 2 & 1 & 19 & 22 & \\
\hline \multicolumn{2}{|c|}{ Grand total } & 9 & 6 & 85 & 100 & 15 \\
\hline
\end{tabular}

Table 2. Relationship of animal factors in disease

\begin{tabular}{lllllll}
\hline S.N. & Factors & Class & Positive & Negative & Percentage & p-value \\
\hline \multirow{2}{*}{1} & \multirow{2}{*}{ Age(years) } & $<5.25$ & 1 & 29 & $3.3 \%$ & 0.032 \\
& & $\geq 5.25$ & 14 & 56 & $20 \%$ & $16.1 \%$ \\
2 & \multirow{2}{*}{ Sex } & Female & 13 & 68 & $10.5 \%$ & 0.544 \\
& & Male & 2 & 17 & $15.4 \%$ & 0.839 \\
& \multirow{2}{*}{ Species } & Buffalo & 12 & 66 & $13.6 \%$ & \\
\hline
\end{tabular}

significance. Prevalence was calculated by percentage of the positive reactors considering all the subjects under study. The association of the factors under study was tested by Fisher's exact test.

\section{RESULTS}

\section{Tuberculin test results}

Among the 78 buffaloes tested, 12 (15.4\%) were found positive. Similarly among the 22 cattle tested, $3(13.6 \%)$ were positive. The detail of tuberculin test result is given on table 1 .

\section{Animal factors in tuberculosis}

The animal factors under consideration were age, sex and species. Sex and species are the dichotomous variables and two classes for age were created with the arithmetic mean as a border line. The relationship of these factors has been studied. There was no significant association of species of animal (cattle or buffalo) with tuberculosis infection $(p>0.5)$.

Total 30 animals less than 5yrs of age and 70 animals above 5 yrs of age were tested. Out of 30,1 (3.3\%) was positive and out of 70, 15 (21.4\%) were found to be positive for tuberculosis infection. Age was found to be significantly $(\mathrm{p}<0.05)$ associated with tuberculosis infection. Among 15 males, 2 (13.3\%) were found to be positive. Similarly, among
85 female, 13 (16\%) were found to be positive. We found no significant association of sex with tuberculosis infection ( $p>0.05)$. The relationship of various animal factors with bTB infection are shown in table 2 .

\section{Knowledge and practices of tuberculosis patients}

From 60 households selected, 70 tuberculosis patients were interviewed. Male patients $(n=53$, $75.7 \%)$ were higher than female patients $(n=17$, $24.3 \%$ ). Bovine tuberculosis was found positive in animals of 15 (25\%) households. The result of questionnaire survey showed that $70 \%$ of farms had mixed cattle/buffalo herding system of farming. All the TB patients were involved in feeding, milking or other farm management procedures that directly exposed them to the animals. $24 \%$ of the patients even had habit of raw milk consumption. $23 \%$ of farmers had heard about zoonotic diseases of some kind but only $9 \%$ knew that tuberculosis can also be a zoonotic. Further, only $6 \%$ of them knew that raw/unpasteurized milk can transmit tuberculosis from animals to human (Table 3).

\section{DISCUSSION}

A total of 100 animals were tuberculin tested. The results were expressed as positive or negative for the analysis. Prevalence among buffaloes and cattle in this study were $15.4 \%$ and $13.6 \%$ 
Table 3. Knowledge and practices of tuberculosis patients

\begin{tabular}{lcc}
\hline & & Responses \\
Parameters & Yes & No \\
& $n(\%)$ \\
Mixed herding system in farm $(\mathrm{n}=60)$ & $42(70 \%)$ & $18(30 \%)$ \\
Positive reactor animals on farm $(\mathrm{n}=60)$ & $15(25 \%)$ & $45(75 \%)$ \\
Habit of raw milk consumption $(\mathrm{n}=70)$ & $17(24 \%)$ & $53(77 \%)$ \\
Knowledge of zoonotic diseases $(\mathrm{n}=70)$ & $16(23 \%)$ & $54(77 \%)$ \\
Heard about zoonotic bovine tuberculosis $(\mathrm{n}=70)$ & $6(9 \%)$ & $64(91 \%)$ \\
Knew raw/unpasteurized milk can transmit tuberculosis $(\mathrm{n}=70)$ & $4(6 \%)$ & $66(94 \%)$ \\
\hline
\end{tabular}

respectively which is greater than previous findings as summarized by Joshi et al. ${ }^{8}$ As per Joshi et. al. overall prevalence on buffalo was $9.08 \%$ and in cattle $5.78 \%$. The higher positive percentage found in this study may be due to the transmission of bacilli in human-animal interface, the animal being raised by tuberculosis patients, which was also reported in Ethiopia. ${ }^{10}$

Among the factors under study, older age of the animal was found to be significantly $(\mathrm{p}<0.05)$ associated with infection. It is in agreement with study results of Ethiopia. ${ }^{11}$ Infection might not have been established in young animals, but as the animals get older, the chance of being infected is higher because of sufficient exposure time. However, difference between sexes and species were not significant ( $p>0.05$ ). The similarity between sexes may be due to similar environment or comparatively few males being included in this study in comparison to a Tanzanian study revealing significant difference between male and female animal. ${ }^{12}$

A large amount of insufficiently pasteurized milk and dairy product are consumed daily in Nepal, and it has been reported that dairy product are contaminated by various pathogens. Jha et. al. had isolated Mycobacterium species from milking buffaloes and cattle in Nepal. Of the 36 strains isolated, 13 were identified as M. bovis. $^{13}$ In our study $24 \%$ of the tuberculosis patients had habit of raw milk consumption. Thus, it is possible for $M$. bovis infection to be transmitted to such people in study area and also in other part of Nepal via dairy product. Mixed herding system of cattle and buffaloes as practiced by maximum farmers further aggravates the possibility of TB transmission in animals and humans. Since most of the farmers either sold their milk to local people or pool milk in units for selling milk products without treating it with heat, risk of milk contamination with M. bovis forms a potential health hazard to consumers in the area.

Knowledge about the disease is very important factor that motivates a person towards prevention and control of diseases. The knowledge and awareness among the tuberculosis patients in this study, however, was very poor. Only $23 \%$ people knew about any sort of zoonotic diseases while even less $9 \%$ knew tuberculosis can be a zoonotic one. Only $6 \%$ of the tuberculosis patients knew that they might have got tuberculosis by consumption of raw/ unpasteurized milk. These findings may be projected as the situation of the entire country, where neither the formal education nor any other informal media has ever attempted to educate the people about bTB and its zoonotic significances.

\section{CONCLUSION}

The study was a screening test of TB in the animals reared by DOTs taking farmer with a limited sample size from a small geographical area of Nepal. However, it is expected that the results obtained is sufficient and useful for the prediction of prevalence of bTB, which might have transmitted from humans to animals or vice versa. Further research is needed to better understand bTB transmission in humans from animals by conformation of $M$. bovis via cultural, biochemical and molecular tests. There should be stronger intersectoral collaboration between the medical and veterinary professions to assess and evaluate the scale of the problem, mostly when zoonotic TB is present.

\section{ACKNOWLEDGEMENT}

We would like to acknowledge all the helping hands from Institute of Agriculture and Animal Science (IAAS), Rampur, Chitwan, DOTS centers and District Public Health Office of Chitwan.

CONFLICT OF INTEREST: None to declare.

FINANCIAL INTEREST: None to declare. 


\section{REFERENCES}

1. Mathews F, Macdonald DW, Taylor GM, et al. Bovine tuberculosis (Mycobacterium bovis) in British farmland wildlife: the importance to agriculture. Proc Biol of the Royal society B 2006;273:357-365.

2. Pollock JM, Neill SD. Mycobacterium bovis infection and tuberculosis in cattle. Vet J 2002;163:115-127.

3. Etter E, Donado P, Jori F, Caron A, Goutard F, Roger F. Risk analysis and bovine tuberculosis, a re-emerging zoonosis. Ann N Y Acad Sci 2006;1081:61-73.

4. Thoen CO, Lobue P, Enarson DA, Kaneene JB, de Kantor IN. Tuberculosis: a re-emerging disease of animals and human. Vet Ital 2009;45:135-181.

5. Ayele WY, Neill SD, Zinsstag J, Weiss MG, Pavlik I. Bovine tuberculosis: an old disease but a new threat to Africa. Int J Tuberc Lung Dis 2004;8:924-937.

6. Boukary AR, Thys E, Abath E, et al. Bovine tuberculosis prevalence survey on cattle in the rural livestock system of Torodi (Niger). PLos One 2011;6: e24629. doi:10.1371/journal.pone.0024629.

7. Radostits OM, Gay CC, Hinchcliff KW, Constable PD. Veterinary Medicine. 10 ${ }^{\text {th }}$ ed. India: Elsevier publishing; 2010.

8. Joshi DD, Heidmann P, Joshi YP, et al. One health program formulation to control any emerging and reemerging zoonotic diseases in Nepal: perspectives of tuberculosis. Presented at the 10th conference of Nepal Veterinary Association. Nepal, 2012.

9. Chakrabarty A. A textbook of preventive veterinary medicine. India: Kalyani Publishers; 1997.

10. Ragassa AY, Ameni G. Sensitivity and specificity of a single intradermal tuberculin test at the cervical and caudal folds in zebu cattle in Ethiopia. Indian J Anim Sci 2001;71:325-327.

11. Ameni G, Miorner H, Tibbo M. Comparison between comparative tuberculin and gamma-interferon tests for the diagnosis of bovine tuberculosis in Ethiopia. Trop Anim Health Prod 2000; 32:267-276.

12. Kazwala RR, Kambarage DM, Daborn CJ, Nyange J, Jiwa SF, Sharp JM. Risk factors associated with the occurrence of bovine tuberculosis in cattle in the southern highlands of Tanzania. Vet Res Commun 2001;25:609614.

13. Jha VC, Morita $\mathrm{Y}$, Dhakal $\mathrm{M}$, et al. Isolation of Mycobacterium spp. from milking buffaloes and cattle in Nepal. J Vet Med Sci 2007;69:819-825.

\section{Citing this article}

Pandey G, Dhakal S, Sadaula A, et al. Status of tuberculosis in bovine animals raised by tuberculosis infected patients in Western Chitwan, Nepal. Int J Infect Microbiol 2012;1(2);47-53. 